\title{
Group Decision Support for e-Mail Service Optimization through Information Technology Infrastructure Library Framework
}

\author{
Yasen Mitev, Leoneed Kirilov* \\ Inst. of Information and Communication \\ Technologies - Bulgarian Academy of Sciences \\ Acad. G. Bonchev Str., bl. 2, 1113 Sofia, Bulgaria \\ Email:1_kirilov_8@abv.bg
}

\begin{abstract}
The e-mail service takes significant part at the corporate collaboration due to its natural benefits like: unification, traceability and the ease of use. To ensure that such a fundamental service is functioning and being maintained right, proper methods for measuring its efficiency and reliability are in place. In this paper we propose a group decision support that allows the IT Management staff to choose proper asset of key performance indicators (KPIs) for measuring the operational performance of the service in a specific organization. A comprehensive set of KPI indicators is proposed for quality assessment of e-mail service. The optimization of the service is done within ITIL framework.

Index Terms-e-mail service, group decision making, ITIL (Information Technology Infrastructure Library), KPI (Key Performance Indicators)
\end{abstract}

\section{INTRODUCTION}

$\mathrm{T}$ HE e-mail service is one of the business critical functions in most of the enterprises. It is being defined as principal communication channel in most of them. This is caused both by productivity and legal reasons.

The Service Level Agreement is one of the key subjects in the Service Design volume of ITIL (Information Technology Infrastructure Library) - [1]. It is an asset of processes that aims to describe the deliverables that should be achieved in order to have the service available on the expected level. The Key Performance Indicators (KPI) are parameters that quantitatively describe the SLA (Service Level Agreement). For example, when we talk for e-mail service following KPI (Key Performance Indicators) [2] may be defined: $99 \%$ of all the e-mail messages to be delivered for less than a minute within the organization; the e-mail servers to be reachable for at least $97,5 \%$ of the time; all the priority 1 service requests to be resolved within 90 minutes; etc.

For the scope of this research we are going to cover the KPIs that fall under the Service Operations volume of ITIL [2]-[4]. Our scenario includes the cases where the e-mail service is already integrated and running in normal operations mode. Key performance indicators can be also used in case of measuring the efficiency of integration of the service or from financial perspective in order to assess the financial efficiency.

\footnotetext{
* Corresponding author
}

\section{Problem Formulation AND OVERVIEW}

The usage of ITIL framework for improving and optimizing the level of the email service have been proved as successful approach [2], [5], [6]. This framework does not give the exact rules itself, it also does not specify the exact measurable for success. Therefore, development and application of appropriate methods is actual task - [7]-[14].

In the case study [15] it has been studied how the service is being recognized before and after the ITIL framework implementation based on a simple KPIs defined in [16] and in that way it is shown the benefits and difficulties from implementing ITIL.

How the customer satisfaction is being evaluated is described in [17]. They construct IT service level evaluation system, based on ITIL. On Fig. 1 it can be seen that the KPI has key effect over the customer's perceptions of the quality of the IT Service. The quality of the ITIL service is dependent both by the customer perceptions and the KPIs form the ITIL based service evaluation framework.

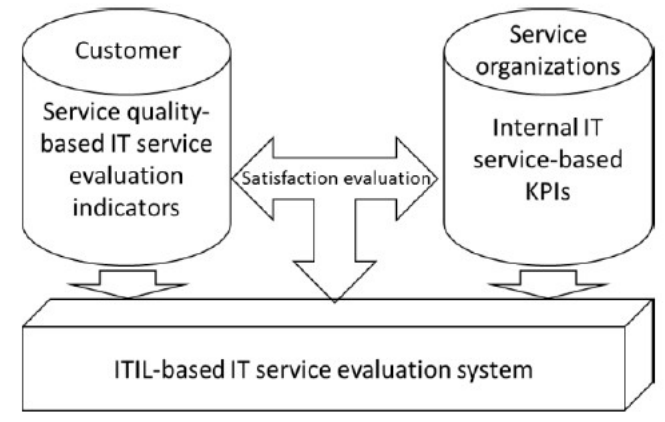

Fig. 1 Satisfaction evaluation for the IT Service - [17]

The proper choosing of the proper KPIs met the following two challenges:

- Usage of the proper asset of KPIs - as there are collaterals suggesting very large lists of KPIs that can describe the properties of the service, it is responsible task to choose the ones that can represent the customer's expectations and priorities. It is a common issue to choose irrelevant KPI metrics that furtherly to be monitored. In that scenario the companies suffer from low customer satisfaction but positive and optimistic values (for example service uptime for more of the expected $98 \%$ of the month). This results in losing company resources to get better in tasks that do not add sig- 
TABLE I.

GROUP DECISION MAKING MODEL FOR KPIS

\begin{tabular}{|c|c|c|c|c|c|c|c|c|c|c|c|c|c|c|c|c|c|c|}
\hline & \multicolumn{3}{|c|}{ Service availability KPI } & \multicolumn{4}{|c|}{ Service request management $\mathrm{KPI}$} & \multicolumn{6}{|c|}{ Incident management KPIs } & \multicolumn{3}{|c|}{ Change management } & \multicolumn{2}{|c|}{ Capacity SLA } \\
\hline & 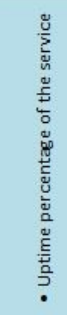 & 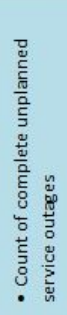 & 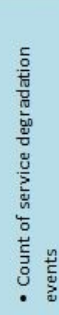 & 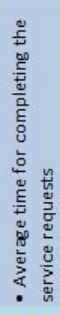 & 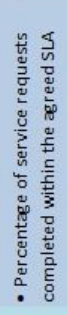 & 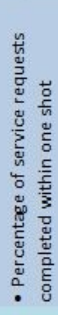 & 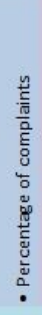 & 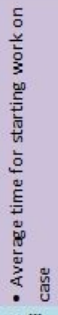 & 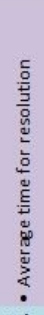 & 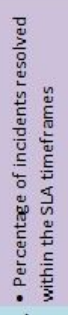 & 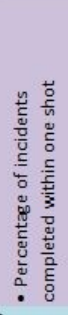 & 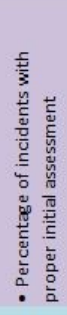 & 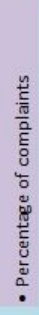 & 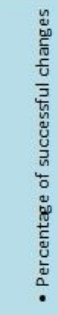 & 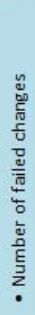 & 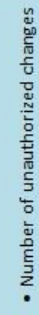 & 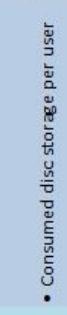 & 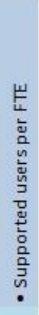 \\
\hline & \multicolumn{18}{|c|}{ Will support the service uptime } \\
\hline IT Director & 10 & 10 & 7 & 3 & 4 & 4 & 6 & 4 & 7 & 9 & 8 & 6 & 8 & 8 & 7 & 10 & 8 & 10 \\
\hline SLA Manager & 7 & 9 & s & 5 & 4 & 4 & 3 & 7 & 4 & 6 & 4 & 4 & 8 & 6 & 8 & 9 & 6 & 8 \\
\hline Incident Manager & 9 & 6 & 7 & 4 & 5 & 5 & 6 & 6 & 3 & 10 & 6 & 8 & 4 & 7 & 9 & 9 & 2 & 4 \\
\hline Problem Manager & 10 & 6 & 7 & 2 & 3 & 1 & 3 & 7 & 8 & 9 & 8 & 8 & 6 & 8 & 8 & 8 & 4 & 6 \\
\hline \multirow[t]{2}{*}{ Change manager } & 9 & 9 & $\epsilon$ & 2 & 3 & 2 & 4 & 8 & 4 & 8 & 6 & 7 & 5 & 10 & 8 & 7 & 6 & 4 \\
\hline & \multicolumn{18}{|c|}{ Will support the end user satisfaction } \\
\hline IT Director & 8 & 8 & $\mathrm{~s}$ & 8 & 7 & 9 & 10 & 7 & 7 & 6 & 10 & 7 & 9 & 7 & 7 & 3 & 3 & 1 \\
\hline SLA Manager & 10 & 6 & 5 & 8 & 5 & 7 & 8 & 3 & 6 & 5 & 7 & 4 & 8 & 4 & 5 & 1 & 2 & 3 \\
\hline Incident Manager & 8 & 7 & $\epsilon$ & 9 & 7 & 8 & 9 & 5 & 8 & 7 & 8 & 5 & 10 & 6 & 6 & 2 & 1 & 3 \\
\hline Problem Manager & 8 & 9 & 6 & 7 & 6 & 9 & 8 & 4 & 4 & 6 & 5 & 2 & 7 & 5 & 4 & 1 & 3 & 2 \\
\hline \multirow[t]{2}{*}{ Change manager } & 9 & 6 & 6 & 7 & 5 & 5 & 8 & 3 & 5 & 5 & 7 & 3 & 7 & 7 & 7 & 4 & 4 & 1 \\
\hline & \multicolumn{18}{|c|}{ Will support the end user productivity } \\
\hline IT Director & 10 & 9 & $\varepsilon$ & 7 & 4 & 2 & 4 & 8 & 8 & 8 & 5 & 3 & 5 & 5 & 5 & 2 & 7 & 3 \\
\hline SLA Manager & 8 & 9 & $\varepsilon$ & 6 & 4 & 2 & 5 & 7 & 6 & 7 & 5 & 4 & 4 & 3 & 3 & 3 & 2 & 2 \\
\hline Incident Manager & 9 & 6 & $\epsilon$ & 5 & 6 & 2 & 3 & 4 & 9 & 9 & 3 & 5 & 6 & 4 & 3 & 1 & 1 & 2 \\
\hline Problem Manager & 8 & 8 & 6 & 3 & 3 & 3 & 3 & 4 & 6 & 4 & 3 & 2 & 7 & 7 & 7 & 3 & 3 & 3 \\
\hline Change manager & 9 & 9 & 5 & 4 & 6 & 3 & 1 & 5 & 7 & 6 & 1 & 1 & 3 & 5 & 4 & 6 & 2 & 5 \\
\hline
\end{tabular}

nificant value to the overall quality of the service, while other important activities are being neglected.

- Setting up the right values for the chosen KPIs - the most often problem here is that after choosing the KPIs that are going to be monitored, they are not assigned with proper values. This leads to committing with objectives that cannot be met by the service supplier. Also, there is a dependency that determining higher value of a service requires higher effort, materials and funding. Because of that reason choosing the right values has economic dependency as well.

\section{Key Performance IndicAtors Design}

The design of KPIs is not a single time activity. There are specific occasions when KPIs need to be implemented, applied, followed up and updated. The IT service lifecycle describes the stages where is an interaction with the KPIs.

The basic approaches that are currently being used by the companies are [18]:

- Usage of the proper asset of KPIs - most of the companies rely on a standard asset of KPIs included in their offering plans. These assets are different for the different companies and correspond to their strengths and maturity. This puts demand to the service so it to be relevant only for particular types of business needs. When non-standard requests come to the implementer/developer, custom KPIs needs to be created to measure the bespoke service.

- Setting up the right values over the chosen KPIs - the goal is to determine thresholds for the different KPIs. They need to correspond to the understanding for acceptable quality of service by both customer and supplier. When obtaining these thresholds, a detailed assessment is being made on the available support resource as well as the supported envi- ronment. There is also a good practice to include additional warning threshold which to flag that high attention is needed for the indicator in order to continue functioning as expected.

Talking about email service there are a couple of groups with KPIs that can be defined. Depending of the business needs only a couple of the KPI can be chosen and also specific ones to can be added. In some of the companies it is extremely important to have high level of data privacy (banking, military) and in another ones the service reliability and the uptime are the most important (logistics, sales), so in the different business areas there are different business requirement for the email service. That leads to the different usage of KPIs for successfully measuring of the level of the support service.

It is important to be noticed that there are also different groups of KPIs for the different chapters of ITIL - [19].

We propose to use for quality evaluation of e-mail service a number of 18 KPIs divided into the following groups (they are detailed in the header of Table I): Service availability; Service request management; Incident management; Change management; Capacity SLA.

\section{Group Decision Making IN KPIS Selection}

The evaluation and selection of corresponding KPIs is the next step of integrating IT service. We apply Group Decision Making approach for this purpose.

The process is summarized in two steps:

I. The group of experts creates a list with all the key performance indicators that may be included in the SLA for the customer. 
TABLE II.

TOP 5 SCORED KPI; LEVEL OF AGREEMENT AND DISAGREEMENT
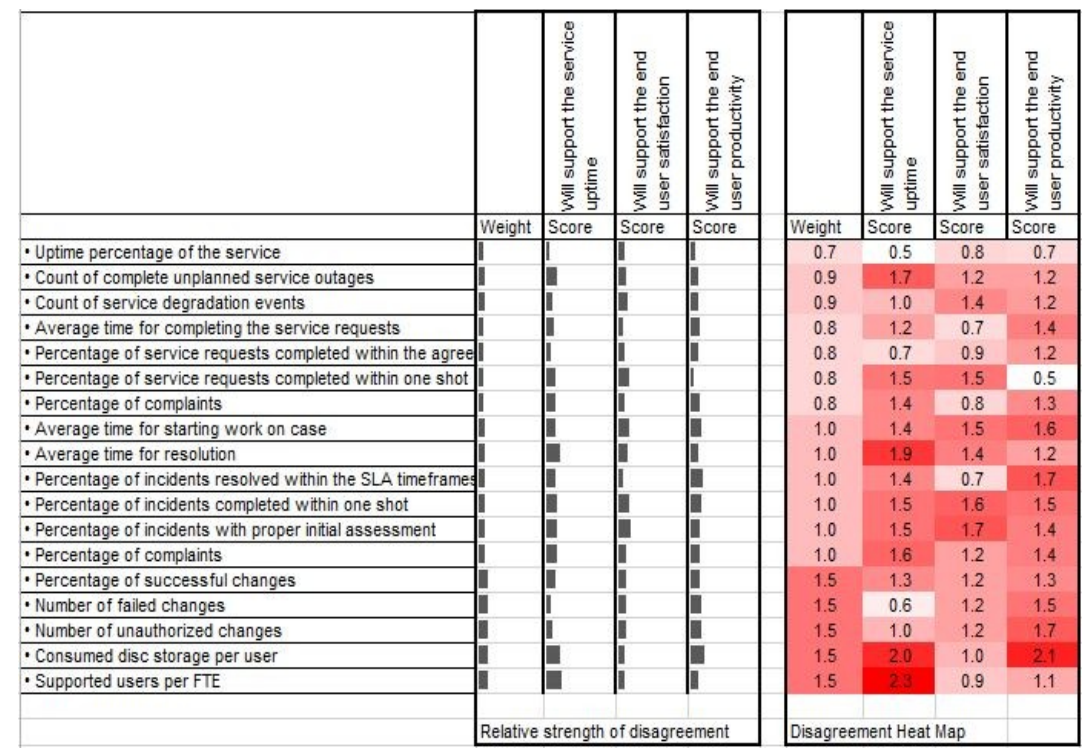
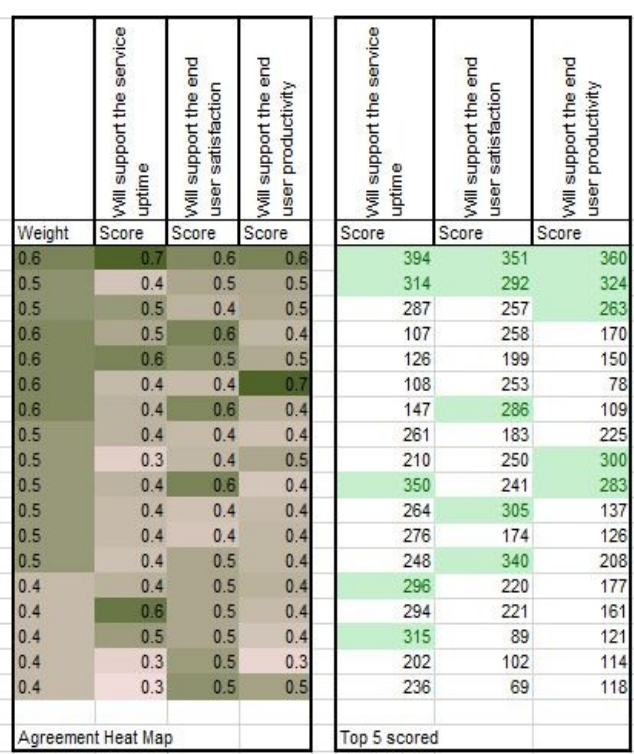

II. The group of experts evaluates the feasibility of the collected KPIs one by one.

We demonstrate the proposed approach on the following real-life problem. There is a need to improve the quality of the IT service in a large national university with $\sim 24000$ students. A number of five experts have been engaged to solve the problem according to the selected KPIs. The experts are part of the university IT department and they have the following roles according to ITIL: IT Director; SLA Manager; Incident Manager; Problem Manager; Change Manager. Additional clarification has been made that the university email service is provided only to the teachers and the personnel and not to the students.

These experts rank each of the indicators with score between 1 and 10 as 1 means that the KPI will not be supportive at all and 10 means that such a KPI will strongly support measuring the organization's performance. Each KPI should be evaluated from 3 aspects - if it is going to support the service uptime, the user satisfaction and the user productivity. This will help the process managers to gain clear overview for which purposes the KPIs can be used during the service operations.

The evaluation is made on the base of the IT Environment of the university as follows: technical infrastructure overview; business goals and ongoing issues.

Technical infrastructure overview: The University contains six buildings in one campus, connected with high broadband WAN network in between. The provided e-mail service is available only for the teachers and the administrative personnel. There are 850 mailboxes created in total. The specific is that there is a very large number of external mail contacts stored in the active directory $\sim 32000$. That is due to the reason that for each student a mail contact is created. These contacts are part of different public distribution lists that describe the different classes and learning groups. Technically the environment is hosted on premise in a dedicated server room. Microsoft Exchange 2010 servers with full redundancy deliver the service.

Business goals: It has been planned to upgrade its environment to Exchange 2013 in order to use the features of the latest version. The goal is to have $0 \%$ outages for the email service during the weekdays. Another goal is to implement the laboratories booking trough the Exchange calendar feature.

Ongoing issues: currently the personnel is complaining that the support desk is engaged with a big delay after the issue is reported - sometimes on the next business day. Another identified issue is the data loss for email items - a big number of the requested mailbox restores are not successful.

Based on the provided description the experts have put their ratings. Consolidated view of group decision making model can be seen on Table I. The columns correspond to the KPIs. The rows correspond to the DMs: DM1 = IT Director, DM2 = SLA Manager and so on. The values a(i,j) in the matrix are the scores of the Decision Maker (i) according to the $\operatorname{KPI}(\mathrm{j})$.

The above model is solved using the group decision support method according to [20]. It provides structured, transparent decision making within a group based on statistical methods. The approach employs a weighted decision matrix with authoritative attributes which leads to an individual decision outcome. The weighting coefficients are used to represent the depth of knowledge for the experts about the area of particular KPI. The solution process consists of three stages: I - Group factor identification; II - Individual scoring; III - Facilitator complies results. The output includes the following data: Disagreement and Agreement heat map; Points of contention; Optimistic/Pessimistic Disagreement; 
Optimistic/Pessimistic support of the final score - see Table II.

It can be seen the top 5 scored KPI indicators for each of the three purposes of the feedback session: support for the service uptime; support the end-user satisfaction; support for the end-user productivity. Also, the levels of agreement and disagreement between the experts about the relevancy of particular KPI according to the heat maps are displayed. More intensive color is about high level of agreement (disagreement) between the experts and vice versa.

Further it can be seen that the service availability KPIs (the first three columns from Table I) have major importance for the 3 measured aspects. This is also aligned with high level of agreement between the experts. Also, the level of disagreement between the experts is relatively high for the top 5 chosen KPIs for measuring the end user productivity and satisfaction (Table II, last two columns). That can be explained with the different point of view on the IT service that the different experts have. Another interesting result is that the experts are confident and have high level of agreement for the KPIs that are scored low (see Table II, agreement heat map). That means that we can confidently confirm which KPIs are not relevant. Namely:

- Will support the service uptime: Percentage of service requests completed within the agreed SLA; Average time for completing the service requests; Average time for starting work on case;

- Will support the end user satisfaction: Number of unauthorized changes; Consumed disc storage per user; Supported users per FTE;

- Will support the end user productivity: Percentage of service requests completed within one shot; Supported users per FTE; Percentage of service requests completed within the agreed SLA.

\section{CONCLUSION}

We have proposed a methodology for selection of KPIs that to ensure improved client satisfaction. Also, a comprehensive catalogue with Key Performance Indicators for measuring the quality of an email services was presented. Thirdly, a methodology based on group decision making approach for evaluating KPIs relevance is applied. This methodology allows the management department in organizations to have structured approach for choosing proper KPIs for measuring the business goals. The methodology is demonstrated on a real-life example for enhancing the quality of e-mail service in a large organization.

\section{REFERENCES}

[1] L. Hunnebeck, ITIL Service Design, The Stationery Office, London, 2011, ISBN 978-0113313051.

[2] M. Talla and R. Valverde, "An Implementation of ITIL Guidelines for IT Support Process in a Service Organization", International Journal of Information and Electronics Engineering, Vol.3, No.3, 2013, ISSN: 2010-3719.
[3] R. A. Steinberg, ITIL Service Operation; The Stationery Office; 2011, London; ISBN 978-0113313075.

[4] B. Trinkenreich and G. Santos, G., "Metrics to Support IT Service Maturity Models - A Case Study", Proceedings of the 17th International Conference on Enterprise Information Systems (ICEIS), (Eds. S. Hammoudi, L. Maciaszek and E. Teniente), vol. 2, p.330-338; 2015, Barcelona, Spain.

[5] W. Guo and Y. Wang, "An Incident Management Model for SaaS Application in the IT Organization.", Proceedings of the Int. Conf. on Research Challenges in Computer Science-ICRCCS '09, pp. 137-140, 2009 ISBN: 978-0-7695-3927-0.

[6] M. Spremic, Z. Zmirak, K. Kraljevic, "IT and business process performance management: Case study of ITIL implementation in finance service industry.", Proc. Of the Int. Conf. on Information Technology Interfaces, 2008, 23-26 June 2008, Dubrovnik, pp. 243 250.

[7] D. Borissova, "Group decision making for selection of k-best alternatives", Comptes rendus de l'Acad'emie bulgare des Sciences, 69 (2), 2016, pp. 183-190.

[8] I. Petrov, "On structural entropy and concentration analysis of industrial and market systems.”, In: (Ed. R. Andreev) Proceedings of the Int. Conference on Big Data, Knowledge and Control Systems Engineering 2016, 11-24, Publisher: Union on Automatics and Informatics, Sofia. ISSN: 2367-6450.

[9] Al. Tsenov, "Approaches for Improvement of IT Systems Management", International Journal of Innovative Science and Modern Engineering (IJISME), 3(6), 2015, pp. 95-98, ISSN: 23196386

[10] I. Popchev, Ir. Radeva. and Ir. Nikolova, "Aspects of the evolution from risk management to enterprise global risk management", Engineering Sciences, LVIII, 2021, No. 1, pp. $16-30$.

[11] P. Weichbroth, "Mining e-mail message sequences from log data", Proceedings of the 2018 Federated Conference on Computer Science and Information Systems, M. Ganzha, L. Maciaszek, M. Paprzycki (eds). ACSIS, Vol. 15, pp. 845-848 (2018), DOI: http://dx.doi.org/10.15439/2018F325

[12] L Kirilov, V Guliashki, K Genova, M Vassileva, B Staykov, "Generalized scalarizing model GENS in DSS WebOptim,", International Journal of Decision Support System Technology (IJDSST) vol. 5, issue 3, 2013, pp. 1-11, DOI: $10.4018 /$ jdsst.2013070101.

[13] J. Rubio and M. Arcilla, "How to Optimize the Implementation of ITIL through a Process Ordering Algorithm", Applied Sciences, 10 (1), 2020, 34; https://doi.org/10.3390/app10010034

[14] J. L. Rubio Sánchez, "Model to Optimize the Decision Making on Processes in IT Departments" Mathematics 9, no. 9: 983. 2021. https://doi.org/10.3390/math9090983

[15] R. Valverde, R. George, S. Talla, M. Talla, "ITIL-based IT service support process reengineering", Intelligent Decision Technologies, pp. 1-20, 2013, IDT-130182.

[16] T. Eikebrokk and J. Iden, "Strategising IT service management through ITIL implementation: model and empirical test", Total Quality Management \& Business Excellence, vol. 28, No 3-4, pp. 238265, 2017.

[17] Y. Xiaozhong, L. Jian and Y. Yong, "Study on the IT Service Evaluation System in ITIL-based Small and Medium-sized Commercial Banks.", International Journal of Hybrid Information Technology, vol. 8, No.4, pp. 233-242, 2015, ISSN: 1738-9968.

[18] C. Pollard and A. Cater-Steel, "Justifications, strategies, and critical success factors in successful ITIL implementations in US and Australian companies: an exploratory study", Information systems management, vol. 26, No 2, pp. 164-175, 2009.

[19] M. Brenner, "Classifying ITIL Processes; A Taxonomy under Tool Support Aspects", Proceedings of the First IEEE/IFIP International Workshop on Business-Driven IT management (BDIM 2006). DOI: 10.1109/BDIM.2006.1649207.

[20] D. Krapohl, "A Structured Methodology for Group Decision Making", 2012 , online http://www.augmentedintel.com/content/articles/group_strategic_deci sion_making_with_weighted_decision_matrix.asp, (last accessed on: .05.2021) 